\title{
Dystocia due to Perosomus elumbis, Brachygnathia, Cleft Plate and Omphalocele in a Buffalo
}

\author{
G. Monica ${ }^{1}$, Cecilia Joseph ${ }^{2}$, T. Sarath ${ }^{2 *}$, B. S. Pradeep Nag ${ }^{1}$ and S. Balasubramanian ${ }^{3}$ \\ ${ }^{1}$ Department of Veterinary Gynaecology and Obstetrics, MVC, Tamil Nadu Veterinary and \\ Animal Sciences University, Chennai-07, Tamil Nadu, India \\ ${ }^{2}$ Department of Clinics, MVC, Tamil Nadu Veterinary and Animal Sciences University, \\ Chennai-07, Tamil Nadu, India \\ ${ }^{3}$ Director of Clinics, MVC, Tamil Nadu Veterinary and Animal Sciences University, \\ Chennai-07, Tamil Nadu, India
}

*Corresponding author

A B S T R A C T

\section{Keywords \\ Perosomus Elumbis, Cleft Palate, Brachygnathia, Omphalocele, Buffalo \\ Article Info \\ Accepted: \\ 15 May 2018 \\ Available Online: \\ 10 June 2018}

\section{Introduction}

Developmental abnormalities of ovum, embryo or fetus occur in all species of domestic animals. Monstrosity is a disturbance of the development that involves various organs and systems which can cause great distortion of the individual (Vegad, 2009). Monstrosities most often cause dystocia in dairy cattle, the commonest example being schistosoma reflexus; next in order of frequency are ankylosed calves, including perosomus elumbis; double monsters; dropsical fetuses, including anasarcous and hydrocephalic calves; and achondroplastic monsters (Arthur et al., 2001). The cause of anomalous development is multifactorial in nature (Rousseaux and Ribble, 1988). The important factors are prenatal viral infections, intra uterine exposure to poisons ingested by the dam, vitamin deficiency like Vitamin A and folic acid, hyperthermia and gene mutation (Ali, 2011).

\section{Case history and clinical observation}

A graded Murrah buffalo in its second parity with the history of advanced pregnancy, 
prolonged straining and also premature rupture of placental membrane was brought to Large Animal Obstetrics ward of Madras Veterinary College Teaching Hospital. Clinical examination revealed normal temperature with decreased pulse rate and

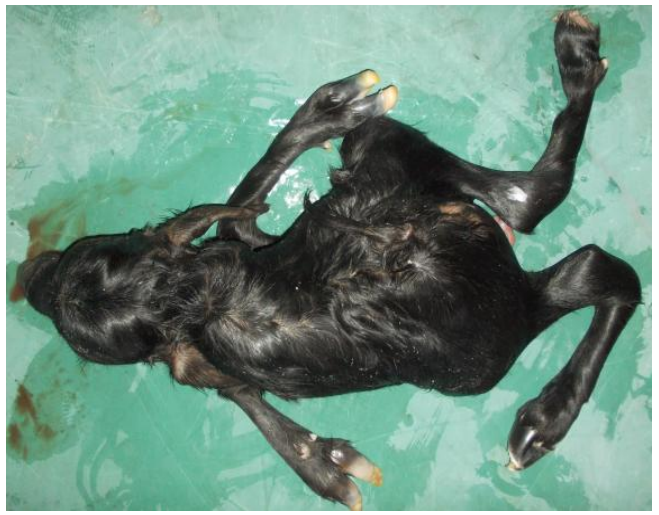

Fig.1: Dead male fetus delivered by simple traction

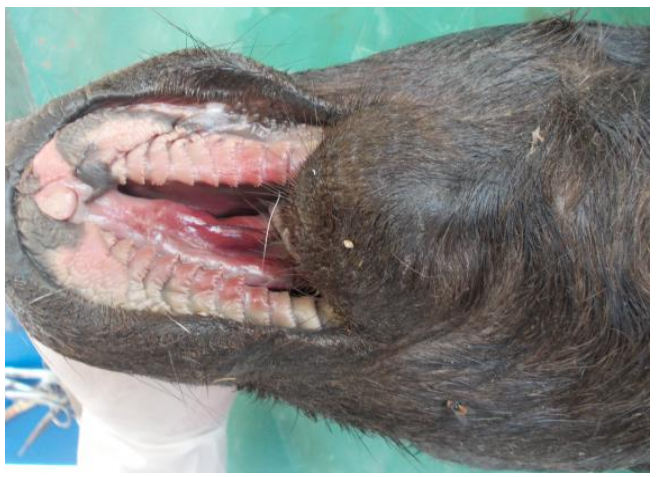

Fig.3: Severe degree of cleft palate

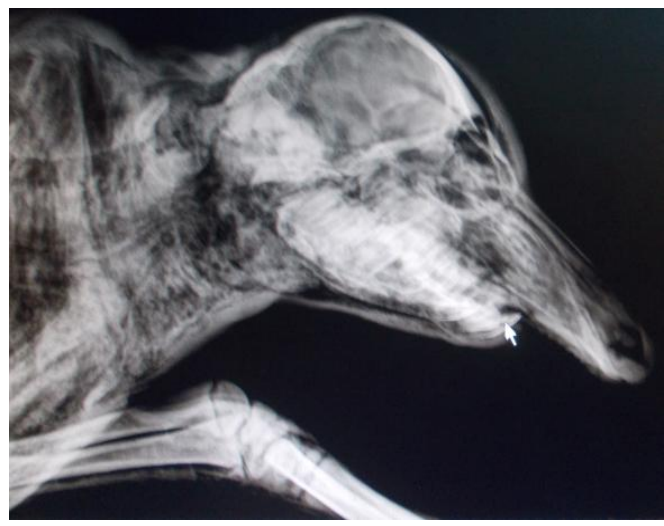

Fig.5: X-Ray showing shortened lower mandible dehydration. Examination per vaginum revealed fetus in posterior longitudinal presentation with bilateral hip flexion and the alignment of hip joints were not normal. So it posed as an occlusion in the passage which caused dystocia.

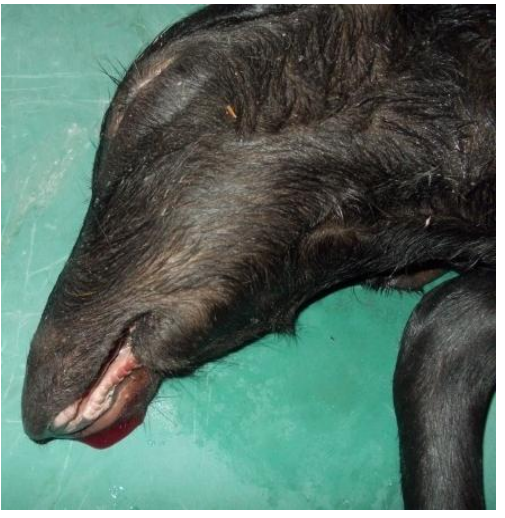

Fig.2: Brachygnathia of lower mandible

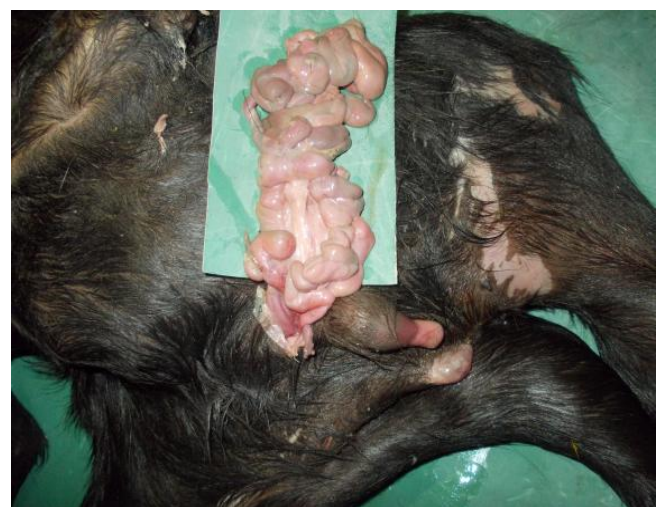

Fig.4: Omphalocele with eviscerated mass

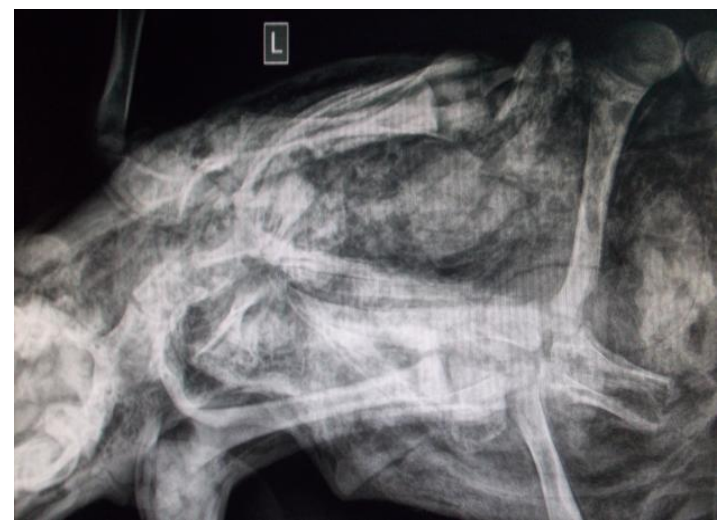

Fig.6: X-Ray showing deformed thoracic, Lumbosacral and pelvic skeleton 


\section{Treatment and Discussion}

Animal was treated with Inj. 5\% Dextrose $2000 \mathrm{ml} \mathrm{IV}$, Inj. Chlorpheneramine maleate $10 \mathrm{ml} \mathrm{IM}$, Inj. 2\% Lignocaine $3 \mathrm{ml}$ epidural. Saturated warm saline solution was administered intra vaginally as there was no room for obstetrical manipulations per vaginum. Liquid paraffin was applied liberally over the fetus. Snares were applied on the fetlock of both limbs and by applying traction, a dead male calf was delivered per vaginally (Fig.1). Animal was then given supportive therapy with Inj.Calcium borogluconate $300 \mathrm{ml}$ (slow) IV, Inj.Melonex $10 \mathrm{ml} \mathrm{IM}$ and Inj.Streptopenicillin $2.5 \mathrm{~g}$ IM. The delivered fetus had brachygnathism (Fig 2), severe cleft palate (Fig.3) and lateral deviation of vertebrae. Partial evisceration (Omphalocele) was noticed through an orifice before the penile region (Fig.4) and further, the hind limbs were ankylosed. As per the characteristic features, the fetus was diagnosed as Perosomus Elumbis and X-ray revealed shortened lower mandible (Fig.5), absence of rib cage-proper, irregularly formed shoulder and hip bones along with poorly, malformed or improper development of thoracic and lumbosacral vertebra (Fig.6).

Perosomus Elumbis is occasionally seen in cattle and swine and is characterized by a lack of vertebrae and spinal cord caudal to the thoracic region. The monster has a small, flattened, deformed pelvis with strongly ankylosed and flexed hind limbs and atrophy of the muscles of the rear quarters (Robert, 2004). This anomaly which has an unknown etiology was first reported in a calf in the veterinary literature in 1832 , and since then many cases have been reported (Jones, 1983). Palate acts as a bridge between oral and nasal passages and cleft palate is a congenital anomaly which poses a life threatening phenomenon compromising with normal feeding. This may develop during late gestation and may be classified as unilateral, bilateral or medial depending upon the severity of the condition. Cleft palate in water buffalos was first reported by Batavani (2005) and it is rarely reported in cattle and buffalo than canine and feline.

Umbilical hernia (omphalocele) in water buffalo is not extensively studied but it may be due to genetic cause for the failure of the umbilicus to close so that peritoneal sac or its contents easily eviscerate through the external orifice at the level of umbilicus (Albarella $e t$ al., 2017).

In anterior presentation, the rigid ankylosed hindlimbs may sometime occlude the passage; it may be mistaken for a breech presentation, posteriorly but with their small, atrophied and loose attachment of the trunk portion, careful and gentle traction can be applied to have a good management while relieving such monsters per vaginum.

\section{References}

Albarella, S., C. Francesca, D. Emanuele, C. Angelo, Z. Luigi and P. Vincenzo. 2017. Review: Congenital Malformations in River Buffalo (Bubalus bubalis). Animals, 7(9): 3-15.

Ali, A.M.H. 2011. Causes and management of dystocia in small ruminants in Saudi Araabia. J. Agric. Vet. Sci., 4(2): 95108.

Amle, M.B., R.R. Shelar, M.G. Thorat and A.N. Zope. 2004. Congenital umbilical hernia and cryptorchidism in a Pandharpuri buffalo calf. Buffalo Bull. 23:82-83.

Arthur, G.H., D.E. Noakes, H. Pearson and T.J. Parkinson, 2001. Veterinary Reproduction and Obstetrics, 8th ed. W.B. Saunders Co. Ltd. London, England. Pp: 132, 133, 303. 
Batavani, R.A. 2005. Cleft palate in buffalo calf (a case report). J. Fac. Vet. Med. Univ. Tehran., 60(3): 303-304.

Jones, T.C. and R.D. Hunt. 1983. Veterinary Pathology, 5th Ed., Lea and Febiger, Philadelphia, Pp: 115.

Robert, S.J. 2004. Veterinary obstetrics and genital diseases. Indian reprints 2004, CBS Publishers and Distributors, Delhi110032.70p.
Rousseaux, C.G. and C.S. Ribble. 1988. Develomental anomalies in farm animals. Can. Vet. J., 29: 30-40.

Shukla, S.P., U.K. Garg, A. Pandey, D.P. Dwivedi and S.P. Nema. 2007. Conjoined twin monster in a buffalo. Indian Vet. J., 84: 630- 631.

Vegad, J.L. 2007. Text Book of Veterinary General Pathology, 2nd ed. International Book Distributions Company. 544p.

\section{How to cite this article:}

Monica G., Cecilia Joseph, T. Sarath, B. S. Pradeep Nag and Balasubramanian S. 2018. Dystocia due to Perosomus elumbis, Brachygnathia, Cleft Plate and Omphalocele in a Buffalo. Int.J.Curr.Microbiol.App.Sci. 7(06): 1796-1799. doi: https://doi.org/10.20546/ijcmas.2018.706.213 